\title{
Phylogenetic study and identification of Vibrio splendidus-related strains based on gyrB gene sequences
}

\author{
Frédérique Le Roux ${ }^{1, *}$, Mélanie Gay ${ }^{1}$, Christophe Lambert ${ }^{2}$, Jean Louis Nicolas ${ }^{3}$, \\ Manolo Gouy ${ }^{4}$, Franck Berthe ${ }^{1}$ \\ ${ }^{1}$ Laboratoire de Génétique et Pathologie, Institut français de recherche pour l'exploitation de la mer (IFREMER), \\ 17390 La Tremblade, France \\ ${ }^{2}$ Laboratoire des Sciences de l'Environnement Marin (LEMAR), Université de Bretagne Occidentale (UBO), \\ Place Copernic, technopole Brest-Iroise, 29280 Plouzané, France \\ ${ }^{3}$ Laboratoire de Physiologie des Invertébrés Marins, IFREMER, 29280 Plouzané, France \\ ${ }^{4}$ Laboratoire de Biométrie et Biologie Evolutive, Unité Mixte de Recherche 5558, Centre National de Recherche Scientifique \\ (CNRS), Université Claude Bernard, Lyon, 43 Boulevard du 11 Novembre 1918, 69622 Villeurbanne cedex, France
}

\begin{abstract}
Different strains related to Vibrio splendidus have been associated with infection of aquatic animals. An epidemiological study of V. splendidus strains associated with Crassostrea gigas mortalities demonstrated genetic diversity within this group and suggested its polyphyletic nature. Recently 4 species, V. lentus, V. chagasii, V. pomeroyi and $V$. kanaloae, phenotypically related to $V$. splendidus, have been described, although biochemical methods do not clearly discriminate species within this group. Here, we propose a polyphasic approach to investigate their taxonomic relationships. Phylogenetic analysis of $V$. splendidus-related strains was carried out using the nucleotide sequences of $16 \mathrm{~S}$ ribosomal DNA (16S rDNA) and gyrase B subunit $(g y r B)$ genes. Species delineation based on 16S rDNA-sequencing is limited because of divergence between cistrons, roughly equivalent to divergence between strains. Despite a high level of sequence similarity, strains were separated into 2 clades. In the phylogenetic tree constructed on the basis of $g y r B$ gene sequences, strains were separated into 5 independent clusters containing $V$. splendidus, V. lentus, V. chagasii-type strains and a putative new genomic species. This phylogenetic grouping was almost congruent with that based on DNA-DNA hybridisation analysis. V. pomeroyi, V. kanaloae and V. tasmaniensis-type strains clustered together in a fifth clade. The gyrB gene-sequencing approach is discussed as an alternative for investigating the taxonomy of Vibrio species.
\end{abstract}

KEY WORDS: Phylogenetic $\cdot G y r B \cdot$ Vibrio splendidus $\cdot$ Polyphyletic $\cdot$ Taxonomy

\section{INTRODUCTION}

Vibrio splendidus (Baumann et al. 1980, Baumann \& Schubert 1984) is widely distributed in marine ecosystems (Nealson et al. 1993, Farto et al. 1999). Several strains have been associated with mortalities of larvae or spat of the scallop Pecten maximus (Nicolas et al. 1996), the turbot Scophthalmus maximus (Gatesoupe et al. 1999) and the oyster Crassostrea gigas (Sugumar et al. 1998, Lacoste et al. 2001, Waechter et al. 2002). An epidemiological study of $V$. splendidus strains associated with $C$. gigas summer mortalities demonstrated the important genetic diversity within this group and suggested its polyphyletic nature (Le Roux et al. 2002). Recently, 4 species ( $V$. lentus, V. chagasii, V. pomeroyi and $V$. kanaloae, phenotypically closely related to $V$. splendidus) have been described (Macian et al. 2001, Thompson et al. 2002, 2003a,b). Given the difficulty in 
identifying these species by means of biochemical methods and tests currently available, the development of genomic methods, congruent with a quantitative DNA-DNA hybridisation method, appeared to be necessary in a polyphasic approach towards species delineation.

Although 16S rDNA sequence analysis is a standard method to hierarchically order prokaryotic taxa among the ranks of genera and kingdoms (Garrity \& Holt 2001, Ludwig \& Klenk 2001, Stackebrandt et al. 2002), results of the $16 \mathrm{~S}$ rDNA-based analysis often do not correlate with DNA-DNA hybridisation, currently recognised as the master criterion for definition of bacterial species (Fox et al. 1992, Stackebrandt \& Goebel 1994). While the ability to translate DNA to protein sequences permits phylogenetic analysis of distantly related strains and more accurate sequence alignment (Gupta 1998), use of protein-coding genes may have several advantages over rDNA. Higher levels of sequence variation allow differentiation of closely related strains (Ochman \& Wilson 1987). DNA gyrase subunit, $g y r B$, is a Type II topoisomerase found in bacteria. Since 1995, when universal primers for this gene

Table 1. Vibrio spp. strains used in this study and EMBL database accession no. In cases where 2 different sequences were obtained for a single strain, these are labelled a and b. LMG: Laboratorium voor Mikrobiologie, Gent, Belgium; CIP: Collection de l'Institut Pasteur, Paris, France; P. m.: Pecten maximus; S. m.: Scophthalmus maximus; C. g.: Crassostrea gigas; N. n.: Nodipecten nodosus; O. e.: Ostrea edulis

\begin{tabular}{|c|c|c|c|c|}
\hline \multirow{2}{*}{$\begin{array}{l}\text { Strain } \\
\text { designation }\end{array}$} & \multirow[t]{2}{*}{ Identification } & \multirow[t]{2}{*}{ Source } & \multicolumn{2}{|c|}{ Accession no. } \\
\hline & & & $16 \mathrm{~S}$ & gyrB \\
\hline \multirow[t]{2}{*}{ LMG $4042^{\mathrm{T}}$} & $V$. splendidus & Marine fishes & a:AJ515229 & \\
\hline & & & b:AJ515230 & AJ515292 \\
\hline PMV18 & $V$. splendidus & P. m. larvae & AJ515224 & AJ515284 \\
\hline PMV19 & $V$. splendidus & P. m. larvae & & AJ577816 \\
\hline \multirow[t]{2}{*}{ A515 } & V. splendidus & P. m. larvae & a:AJ515222 & \\
\hline & & & b:AJ515223 & AJ515283 \\
\hline LT06 & V. splendidus & P. m. larvae & AJ515221 & AJ515282 \\
\hline CIP107166 ${ }^{\mathrm{T}}$ & $V$. lentus & O. e. & AJ294421 & AJ515293 \\
\hline VS6 turb & $V$. lentus & S. m. larvae & AJ515228 & AJ515288 \\
\hline \multirow[t]{2}{*}{ A053 } & $V$. lentus & P. m. larvae & a:AJ515225 & \\
\hline & & & b:AJ515226 & AJ515286 \\
\hline $\mathrm{VC1}$ & $V$. lentus & $P . m$ larvae & AJ515227 & AJ515287 \\
\hline LMG $21353^{\mathrm{T}}$ & V. chagasii & S. m. larvae & AJ316199 & AJ577820 \\
\hline TNEMF6 & V. chagasii & C. g. spat 1997 & AJ515218 & AJ515264 \\
\hline TNNIII7 & V. chagasii & C. g. spat 1997 & AJ515219 & AJ515265 \\
\hline LMG 16745 & V. chagasii & Marine fishes & & AJ515278 \\
\hline LMG $20537^{\mathrm{T}}$ & $V \cdot$ pomeroyi & N. $n$. & AJ491290 & AJ577822 \\
\hline LMG $20539^{\mathrm{T}}$ & V. kanaloae & O. e. & AJ316193 & AJ577821 \\
\hline LMG $20012^{\mathrm{T}}$ & V. tasmaniensis & Marine fishes & AJ316192 & AJ577823 \\
\hline Mel 13 & Unknown & C. g. spat 2001 & & AJ577817 \\
\hline Mel 107 & Unknown & C. g. spat 2001 & & AJ577818 \\
\hline Mel 108 & Unknown & C. g. spat 2001 & & AJ577819 \\
\hline
\end{tabular}

became available, several publications have suggested that $g y r B$ provides suitable sequence data for bacterial phylogenies, possessing essential attributes such as limited horizontal transmission and presence in all bacterial groups (Yamamoto \& Harayama 1995, Watanabe et al. 2001).

In this study, phylogenetic analysis of Vibrio splendidus-related strains was carried out by means of biochemical identification, gyrB and 16S rDNA-gene sequence analyses and quantitative DNA-DNA hybridisation.

\section{MATERIALS AND METHODS}

Bacterial strains and growth conditions. The 19 strains used in this study are presented in Table 1 and were isolated from scallops Pecten Maximus, turbots Scophthalmus maximus and oysters Crassostrea gigas during mortality outbreaks, or purchased from national collections (LMG: Laboratorium voor Mikrobiologie, Gent, Belgium; CIP: Collection de l'Institut Pasteur, Paris, France). Strains were maintained on marine agar 2216 (Difco) at $4^{\circ} \mathrm{C}$ or stored frozen in marine broth 2216 (Difco) supplemented with $10 \%$ (v/v) glycerol (Sigma) at $-80^{\circ} \mathrm{C}$. Incubations and sub-cultures were at $20^{\circ} \mathrm{C}$ on marine agar 2216 (Difco). Strains are maintained in the European Community Reference Laboratory for Molluscs Diseases as part of the collections (Centre de Ressources Biologiques, Laboratoire de Génétique et Pathologie, Institut français de recherche pour l'exploitation de la mer [Ifremer], La Tremblade, France).

Phenotypic characterisation. Phenotypic profiles of strains were determined with classical biochemical tests: Gram-staining (Gram kit; Biomerieux); oxidase (bactident oxidase; Merck); respiratory activity (meat liver medium; Diagnostic Pasteur); commercial kits API 20E and API $50 \mathrm{CH}$ (Biomerieux); glucose metabolism (MEVAG, Diagnostic Pasteur); motility; $\mathrm{NaCl}$ requirement and tolerance $(0,2,4,6,8,10 \% \mathrm{w} / \mathrm{v})$ and temperature tolerance $(4,20,35$ and $40^{\circ} \mathrm{C}$ ) were performed in $1.5 \%(\mathrm{w} / \mathrm{v})$ peptone broth (Diagnostic Pasteur).

Tests were coded as 1 (positive result) or 0 (negative result) and numerical analysis was performed using 
simple matching coefficients (Sneath 1972) and an unweighted pair-group method (Sneath \& Sokal 1973).

Extraction of genomic DNA, amplification, cloning and sequencing of DNA. Genomic DNA was prepared according to Sambrook et al. (1989). PCR amplification of $16 \mathrm{~S}$ rDNA and gyrB was achieved with primers, and following methods previously described (Yamamoto \& Harayama 1995, Lambert et al. 1998). Amplified products were inserted in the pCR2.1 Vector System (Invitrogen) and used to transform Escherichia coli cells. We selected 2 to 4 colonies per strain and gene; minipreps of recombinant plasmids were performed according to standard alkaline-lysis protocols, with an additional phenol/chloroform extraction step and ethanol precipitation (Sambrook et al. 1989). Sequencing was carried out using the Sequiterm Excell II kit (Epicentre) and a Li-cor DNA sequencer (ScienceTec) according to the manufacturer's instruction.

Phylogenetic analyses. 16S rDNA and gyrB sequences were aligned and phylogenetic analyses were performed using Seaview and Phylo-win programs (Galtier et al. 1996). Phylogenetic trees were built using the BIONJ method (Gascuel 1997) applied to Kimura's 2-parameter distances. Reliability of topologies was assessed by the bootstrap method with 1000 replicates. When 2 different sequences were obtained for a single strain, they were labelled a and $b$ in the phylogenetic tree.

Quantitative DNA-DNA hybridisations. We used and compared 2 methods for DNA-DNA hybridisation experiments. Labelling of DNA probes with tritium- labelled nucleotides was performed by the random primer method (Megaprime labelling kit) and hybridisation was carried out at $60^{\circ} \mathrm{C}$ by the S1-nuclease method (Crosa et al. 1973, Grimont et al. 1980) with adsorption of S1-resistant onto DE81 filters (Whatman). A second hybridisation method was performed by a non-radioactive dot-blot method described previously (Macian et al. 2001, Le Roux et al. 2002). Statistical analyses were performed using Statgraphics software, Version 5.1. The relation between $\operatorname{gyrB}$ sequencing and DNA-DNA hybridisation (S1-nuclease method) was calculated using a reciprocal model, whereas the comparison of the 2 DNA-DNA hybridisation methods was carried out using a linear model.

\section{RESULTS}

\section{Phenotypic characterisation}

Phenotypic analysis, based on 80 biochemical tests, confirmed the relatedness of the 19 strains included in this study (70\% similarity). The 19 discriminating tests were: $\beta$-galactosidase, arginine dihydrolase, tryptophan desaminase, acetoin production, oxidation/ fermentation of saccharose, melibiose, amygdaline, glycerol, galactose, N-acetyl glucosamine, esculine, celibiose, amidon, gluconate, $\mathrm{NO}_{2}$ production, growth at 4,35 and $40^{\circ} \mathrm{C}$ and $6 \% \mathrm{NaCl}$ (Table 2). The results are presented as a dendrogram using simple matching-similarity coefficients (Fig. 1).

Table 2. Vibrio splendidus. Phenotypic characteristics of the 19 strains examined in this study. Only results of discriminant tests are shown. 1: $\beta$-galactosidase; 2 : arginine dihydrolase; 3 : tryptophan desaminase; 4 : acetoin production; oxidation/fermentation of 5: saccharose; 6: melibiose; 7: amygdaline; 8: glycerol; 9: galactose; 10: N-acetyl glucosamine, 11: esculine; 12: celibiose; 13: amidon; 14: gluconate; 15: $\mathrm{NO}_{2}$ production; growth at $16: 4^{\circ} \mathrm{C}_{i} 17: 35^{\circ} \mathrm{C}_{;} 18: 40^{\circ} \mathrm{C}_{i} 19: 6 \% \mathrm{NaCl}$

\begin{tabular}{|c|c|c|c|c|c|c|c|c|c|c|c|c|c|c|c|c|c|c|c|}
\hline Strain designation & 1 & 2 & 3 & 4 & 5 & 6 & 7 & 8 & 9 & 10 & 11 & 12 & 13 & 14 & 15 & 16 & 17 & 18 & 19 \\
\hline LMG $4042^{\mathrm{T}}$ & + & - & - & - & - & + & + & + & + & + & + & + & + & - & - & + & + & - & - \\
\hline PMV18 & + & + & - & - & - & - & + & + & + & + & + & + & + & - & + & + & - & - & - \\
\hline PMV19 & + & + & - & - & - & - & + & + & + & + & + & + & + & - & + & + & + & - & - \\
\hline A515 & + & + & + & - & - & + & + & + & + & + & + & + & + & - & + & + & - & - & - \\
\hline LT06 & + & + & + & + & + & - & + & - & + & + & + & + & + & - & + & + & - & - & - \\
\hline CIP107166 ${ }^{\mathrm{T}}$ & + & - & - & - & - & - & - & - & - & - & - & - & - & - & - & - & - & - & - \\
\hline VS6 turb & - & + & - & - & - & - & + & + & + & + & + & + & + & - & + & - & - & - & - \\
\hline A053 & + & + & - & - & - & - & + & - & + & + & - & + & + & - & + & + & - & - & - \\
\hline $\mathrm{VC} 1$ & + & + & - & - & - & - & + & - & + & + & + & + & + & - & + & - & - & - & - \\
\hline LMG $21353^{\mathrm{T}}$ & - & + & + & - & + & - & - & - & - & + & + & + & + & - & - & - & - & - & + \\
\hline TNEMF6 & - & + & + & - & - & - & + & + & + & + & + & + & + & + & + & + & + & - & - \\
\hline TNNIII7 & - & + & + & - & - & - & + & - & + & + & + & + & + & + & + & - & + & - & - \\
\hline LMG 16745 & - & + & - & - & - & - & + & + & + & + & + & + & + & - & + & - & + & - & + \\
\hline LMG $20537^{\mathrm{T}}$ & + & + & + & - & - & - & + & - & + & + & + & + & + & - & - & + & - & - & + \\
\hline LMG $20539^{\mathrm{T}}$ & + & + & + & - & + & - & + & - & + & + & + & + & + & - & - & + & + & + & + \\
\hline LMG $20012^{\mathrm{T}}$ & - & - & - & - & - & - & - & - & - & + & + & + & - & - & + & - & - & - & + \\
\hline Mel 13 & - & + & - & - & - & + & + & + & + & + & + & + & + & - & + & + & - & - & - \\
\hline Mel 107 & - & + & - & - & + & + & + & + & + & + & + & + & + & + & + & + & - & - & - \\
\hline Mel 108 & - & + & - & - & + & + & + & + & + & + & + & + & + & + & + & + & - & - & - \\
\hline
\end{tabular}



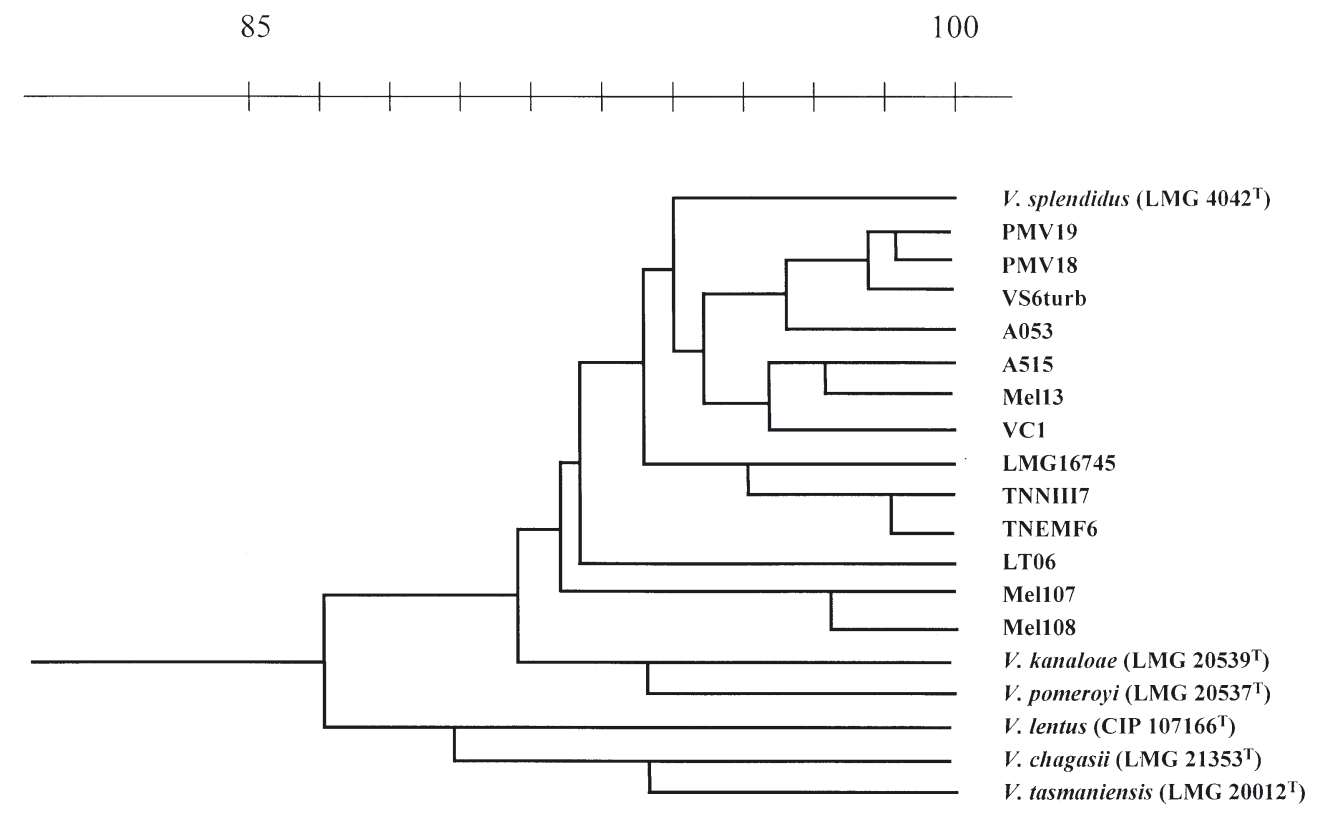

Fig. 1. Vibrio spp. Cluster-analysis of phenetic data using simple matching-similarity coefficient and unweighted pair-group method (percentage in top abscissa) for 18 strains related to $V$. splendidus

\section{Phylogenetic analysis based on 16S rDNA}

The 16S rDNA fragments were amplified and cloned. The sequences used for constructing the phylogenetic tree were 1332 gap-free sites in length. The 4 sequences obtained from each strain were similar, except for A053, A515 and LMG 4042 ${ }^{\mathrm{T}}$, for which polymorphism ( $2 \%$ divergence) was observed. This polymorphism involved an Hha1 restriction site, and PCR-RFLP (restriction fragment-length polymorphism) on other clones confirmed this result (data not shown). Despite a high level of sequence similarity (98\%), a cluster comprising 3 strains: TNEMF6, TNNIII7 and Vibrio chagasii-type Strain LMG $21353^{\mathrm{T}}$ was supported by a bootstrap value of $96 \%$ (Fig. 2). In this phylogenetic tree the $V$. lentus type strain clustered with the V. splendidustype strain, suggesting that $16 \mathrm{~S}$ rDNA sequenceanalysis does not differentiate these 2 species.

\section{Phylogenetic analysis based on gyrB}

The $g y r B$ fragments were amplified and cloned. The sequences used in constructing the phylogenetic tree were 1064 gap-free sites long. Sequences of different cloned fragments obtained from previous strains were similar. The phylogenetic tree based on the gyrB nucleotide sequences from Vibrio splendidus-related strains confirmed clustering of LMG $21353^{\mathrm{T}}$, TNEMF6 and TNNIII7 (Fig. 3). Within this clade, clustering of TNEMF6, TNNIII7 and LMG 16745 was supported by a bootstrap value of $93 \%$. A second clade, supported by a bootstrap value of $100 \%$, comprised 3 strains isolated from Crassostrea gigas: Mel 108, Mel 107 and Mel 13. A third clade, with a bootstrap value of $100 \%$, comprised V. splendidus-type strain (LMG $\left.4042^{\mathrm{T}}\right)$, LT06, A515, PMV18 and PMV19. A 4th clade comprised $V$. lentus-type strain and A053, VS6turb, and VC1. V. kanaloae, V. pomeroyi and V. tasmaniensistype strains were clearly separated from this 4 th clade, and clustered together in a fifth clade. Similar results were obtained by 3 methods: neighbour-joining, maximum parsimony and maximum-likelihood analysis (data not shown).

Table 3. Vibrio splendidus. Intraspecific DNA-DNA homology among strains of 3 clades in $V$. splendidus group determined by (a) S1-nuclease method and (b) the dot-blot method

\begin{tabular}{|c|c|c|c|c|c|c|}
\hline \multirow[t]{2}{*}{ Test strain } & \multicolumn{2}{|c|}{$\begin{array}{l}\text { Probe } \\
\text { TNEMF6 }\end{array}$} & \multicolumn{2}{|c|}{$\begin{array}{c}\text { Probe } \\
\text { LMG } 4042^{\mathrm{T}}\end{array}$} & \multicolumn{2}{|c|}{$\begin{array}{l}\text { Probe } \\
\text { A053 }\end{array}$} \\
\hline & $\mathrm{a}$ & $\mathrm{b}$ & $\mathrm{a}$ & $\mathrm{b}$ & $\mathrm{a}$ & $\mathrm{b}$ \\
\hline LMG $4042^{\mathrm{T}}$ & 40 & 40 & 100 & 100 & 64 & 56 \\
\hline PMV18 & & 47 & 75 & 84 & & 70 \\
\hline A515 & & 37 & 85 & 70 & & 54 \\
\hline LT06 & & 44 & 64 & 86 & & 57 \\
\hline CIP107166 & 39 & & 53 & & 79 & \\
\hline A053 & & 38 & & 53 & 100 & 100 \\
\hline VC1 & & 35 & & 50 & 75 & 90 \\
\hline TNEMF6 & 100 & 100 & & 40 & & 49 \\
\hline TNNIII7 & 83 & 92 & 44 & 35 & 39 & 50 \\
\hline LMG 16745 & 63 & 79 & & & & \\
\hline
\end{tabular}




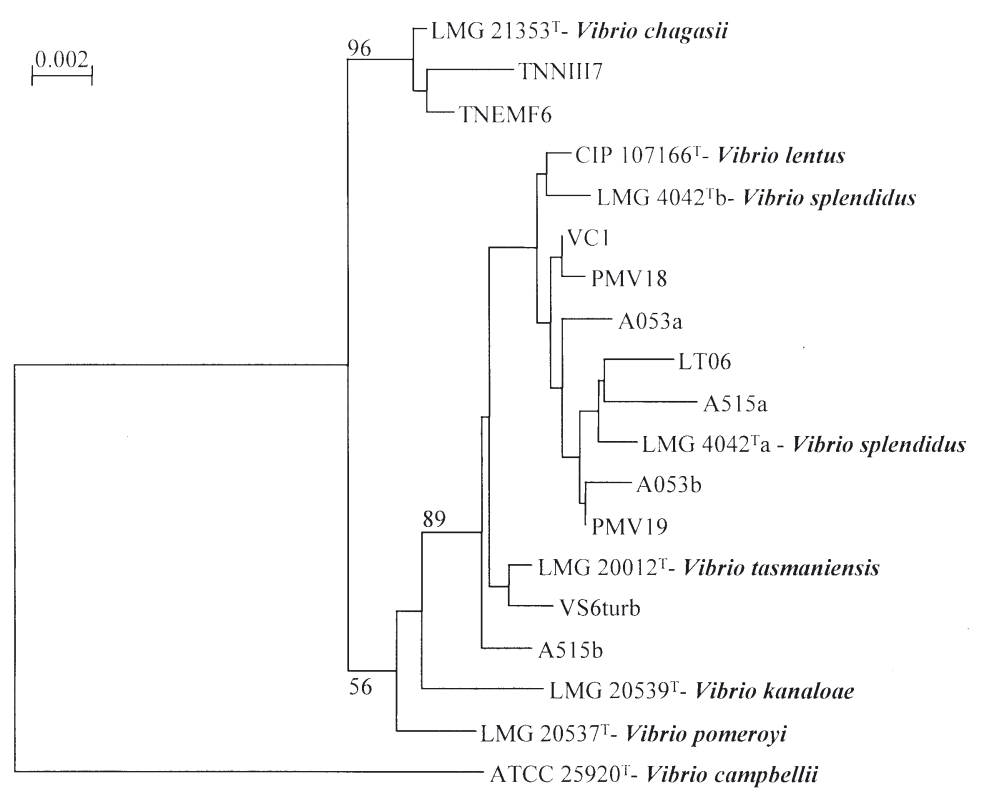

Fig. 2. Vibrio spp. Phylogenetic tree of partial 16S rDNA sequences. V. campbellii homologue was used as outgroup (EMBL accession no. X56575); 1332 gap-free sites were compared. Horizontal branch lengths are proportional to evolutionary divergence. Bootstrap values (as \% of 1000 replicates) appear next to corresponding branch when $>50 \%$. In cases where 2 different sequences were obtained for a single strain, these are labelled a and $b$

\section{DNA-DNA hybridisation}

We used 2 methods of DNA-DNA hybridisation, S1-nuclease and dot-blot, to analyse genomic relatedness between isolates and type strains among 3 clades revealed by the phylogenetic tree in Fig. 3 .

A first hybridisation was performed with strains LMG 4042 ${ }^{\mathrm{T}}$, CIP $107166^{\mathrm{T}}$, TNEMF6, TNNIII7 and LMG 16745 using labelled TNEMF6 DNA as a probe. High rates of hybridisation were obtained with the dotblot method, with percentages of re-association of 92 and $79 \%$ for TNNIII7 and LMG 16745 respectively (Table 3 ). Using the S1 nuclease method, the rates of hybridisation were 83 and $63 \%$ respectively. With both methods the re-association percentage was lower with LMG $4042^{\mathrm{T}}$ and CIP $107166^{\mathrm{T}}$, i.e. 40 to $39 \%$ respectively.

A second set of hybridisations was performed with strains LMG 4042 ${ }^{\mathrm{T}}$, PMV18, A515, LT06, CIP $107166^{\mathrm{T}}$, TNEMF6 and TNNIII7, using LMG $4042^{\mathrm{T}}$ as a probe. Again, higher rates of hybridisation were obtained with the dot-blot method with percentages of re-association above $70 \%$ for
PMV18, A515 and LT06. Hybridisation with TNEMF6 was lower, i.e. $40 \%$. With the S1 nuclease method, rates of hybridisation for the strains belonging to Vibrio splendidus ranged between 64 and $85 \%$, and hybridisation with species from the other clade was between 44 and $53 \%$.

A third set of hybridisations was performed with LMG $4042^{\mathrm{T}}$, CIP $107166^{\mathrm{T}}$, A053, VC1, TNEMF6 and TNNIII7, using labelled A053 DNA as a probe. The S1nuclease method showed percentages of reassociation above $75 \%$ for CIP $107166^{\mathrm{T}}$ A053 and VC1. Hybridisation with TNNIII7 was lower, $39 \%$. This result was confirmed by the second method.

\section{Comparison of methods}

A reciprocal model was used to compare gyrB sequencing and DNA-DNA hybridisation using the S1-nuclease method (Fig. 4a). The adjusted model was: gyrB sequence $=109.188-917.844 /$ hybridisation. The ANOVA probability value was $<0.01$, and adjustment between these 2 methods was statistically significant at the

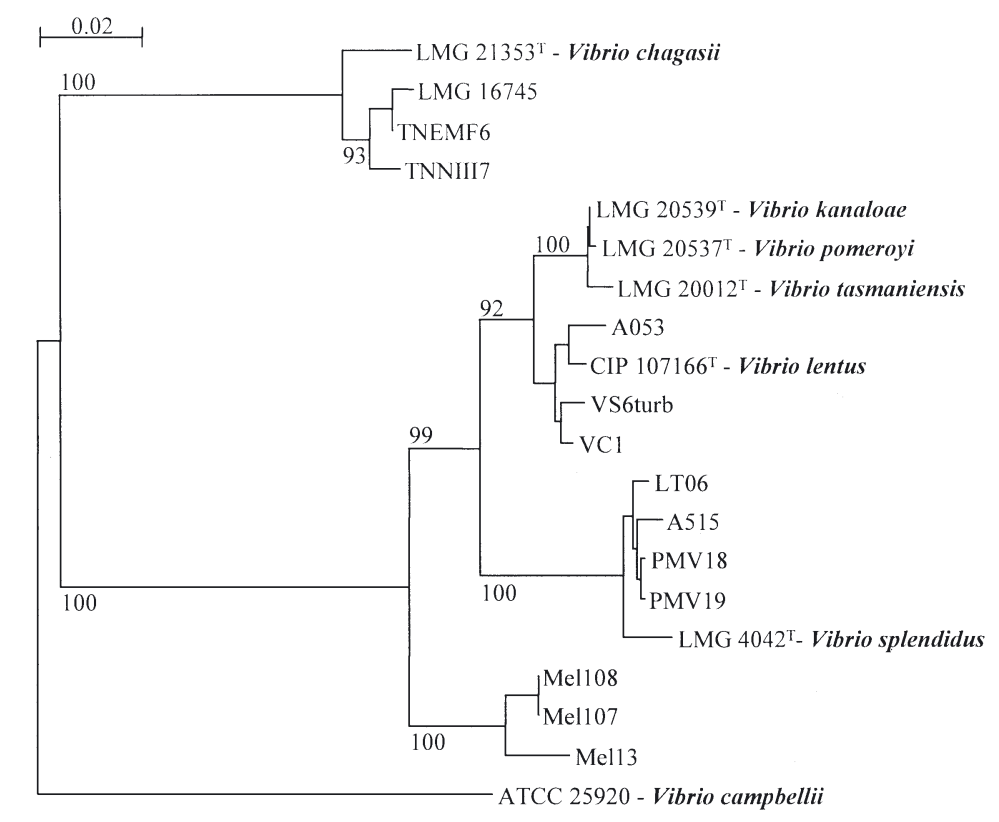

Fig. 3. Vibrio spp. Phylogenetic tree of partial gyrB sequences. V. campbellii homologue was used as outgroup (EMBL accession no. ABO 14950); 1064 gap-free sites were compared. Other features as in Fig. 2 
a

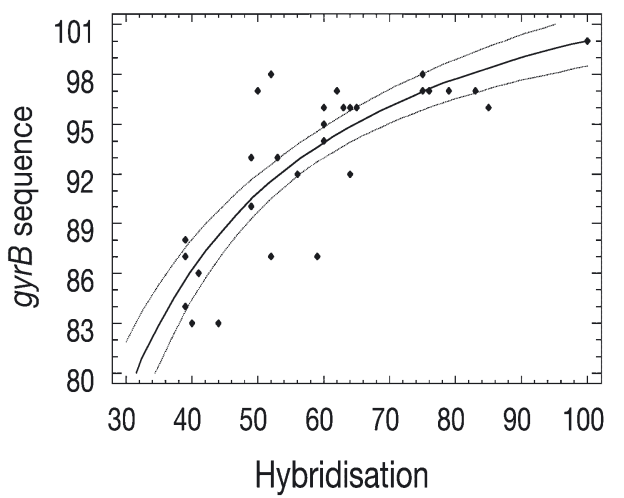

b

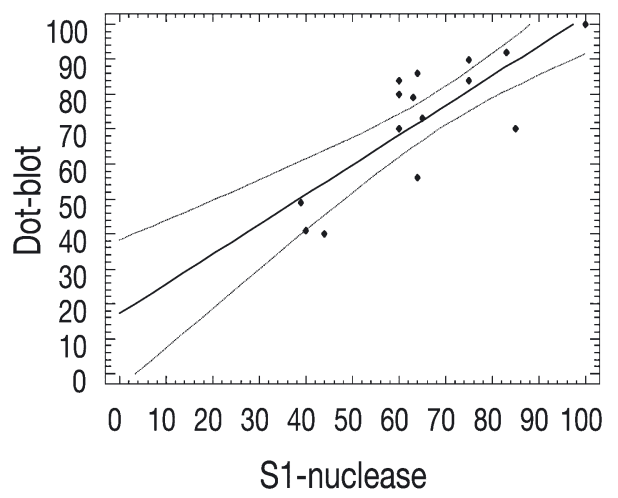

Fig. 4. Comparison of methods. (a) Reciprocal model used to compare gyrB sequencing and DNA-DNA hybridisation in Vibrio splendidus using S1-nuclease (\% hybridisation in abscissa; \% sequence similarities in ordinate); (b) linear model comparing

S1-nuclease and dot-blot methods for determining DNA-DNA hybridisation (\% hybridisation in abscissa and ordinate)

$99 \%$ confidence level. The coefficient of correlation was 0.86 .

A linear model was used to compare the 2 methods of DNA-DNA hybridisation (Fig. 4b). The adjusted equation was dot-blot $=17.1881+0.851149 \times$ S1-nuclease. The ANOVA probability value was $<0.01$, and adjustment between these 2 methods was statistically significant at the $99 \%$ confidence level. The coefficient of correlation was 0.84 .

\section{DISCUSSION}

Different strains related to Vibrio splendidus have been increasingly associated with infection of aquatic species (Sugumar et al. 1998, Gatesoupe et al. 1999, Lacoste et al. 2001, Waechter et al. 2002). As aquaculture production is highly vulnerable to the impact of infectious diseases, the prophylactic approach is of central importance. Given this, it is necessary to develop new diagnostic tests to detect specific pathogens in fishes, shellfishes and the environment, and to monitor the spread and evolution of diseases. In this context, definition and identification of bacterial species and strains raise taxonomy to its pivotal role.

Most of the Vibrio splendidus-related strains are generally identifiable only by means of phenotypic characterisation. This study has confirmed that the biochemical tests currently available are not sufficiently discriminatory to distinguish between strains of $V$. splendidus, $V$. lentus, $V$. chagasii, $V$. pomeroyi and $V$. kanaloae species. Even though descriptions of new species based on biochemical tests of relatively low numbers of strains may provide a discriminatory basis, these tests prove highly variable when applied to a broader spectrum of strains belonging to this species. This could be due to metabolic versatility of strains exposed to variations in the marine environment. Bacterial identification procedures should take this into consideration by incorporating DNA-based methods. A polyphasic approach using molecular techniques is now widely recognised and recommended for species definition (Thompson et al. 2001, Stackenbrandt et al. 2002). This should provide new identification tools for use in diagnostic laboratories.

Our preliminary phylogenetic study was based on partial 16S rDNA gene sequences. The results are in accordance with those of previous studies showing that 16S rDNA sequences of Vibrio splendidus-related strains are very similar (Macian et al. 2001, Le Roux et al. 2002, Waechter et al. 2002, Thompson et al. 2003a, b). They would confirm the current opinion that $16 \mathrm{~S}$ rDNA sequences essentially permit phylogenetic analysis of distantly related strains (Gupta 1998) are probably less effective in identifying closely related strains or even species. In our study, only 1 cluster, containing the $V$. chagasii-type strain, was supported by a high bootstrap value. Sequence dimorphism was observed for several strains (Fig. 1), possibly resulting from microheterogeneity between cistrons (Fox et al. 1992), whereby divergence between cistrons is equivalent to divergence between strains. Therefore, these strains cannot be identified from our data. Bearing in mind the above limitations, the use of protein-coding genes as a data source was considered in the following analysis.

Fig. 3 shows the phylogenetic grouping based on gyrB sequences. The grouping is supported by strong bootstrap values and almost consistent with the results achieved with the quantitative DNA-DNA hybridisation method (Table 3). The primary indication is that strains phenotypically related to Vibrio splendidus can belong to distinct species, which strongly supports the suggested polyphyletic nature of $V$. splendidus and a 
diversity of potentially new species related to V. splendidus (Macian et al. 2001, Thompson et al. 2001, 2003a,b, Le Roux et al. 2002).

Strains belonging to Vibrio splendidus, V. lentus and $V$. chagasii species were clearly separated. The delineation of TNEMF6, TNNIII7 and LMG 16745 from $V$. chagasii is suggested by a high bootstrap value in the gyrB phylogenetic tree. However, further studies including more strains from these 2 groups and DNA-DNA hybridisation data are necessary to test the validity of our results. Our data also suggest that Mel 108, Mel 107 and Mel 13 belong to a new taxon. Here again, further DNA-DNA hybridisation is needed, and in a further study currently in progress we hope to confirm these results and possibly determine 1 or more new species.

For Vibrio pomereyi, V. kanaloae and V. tasmaniensis, our gyrB based analysis appears less discriminative than fluorescent-amplified fragment-length polymorphism (FAFLP) fingerprintings applied to this group (Thompson et al. 2001, 2003a,b). Further work incorporating more strains belonging to these species should be conducted to compare these 2 approaches.

Quantitative DNA-DNA hybridisation is still the recognised reference method for bacterial systematics (Grimont 1984). In our study, we used and compared 2 different methods, namely S1-nuclease and dot-blot. Although the results were well-correlated, the dot-blot method frequently yielded higher rates of reassociation than the S1-nuclease method (Table 3). The S1-nuclease method, using enzyme activity to digest single-stranded DNA, is probably more accurate, avoiding counts of partially hybridised probe. Hybridisation rates between 2 strains varied as a function of method (S1-nuclease/dot-blot). This raises the issue of the thresholds currently accepted for species recognition, since values may vary with method employed. For instance, the probe A053 gave a 90\% hybridisation rate with VC1 using the dot-blot method, but $75 \%$ with the S1-nuclease method. Thus, in view of the fact that dot-blot results probably overestimate the homology and that the S1-nuclease method was not validated by a $\Delta \mathrm{Tm}$ (evaluation of hybrid stability) calculation (Grimont 1984), VC1 and A053 cannot be considered to comprise a single species. However within the framework of this study, DNA-DNA hybridisations were used as tendency indicators to validate phylogenetic constructions based on gyrB gene sequences; e.g. PMV18 displayed $84 \%$ hybridisation with Vibrio splendidus-type strain compared to $70 \%$ for A053 and $47 \%$ for TNEMF6, which was in line with the phylogenetic $g y r B$ analyses.

A problem associated with quantitative DNA-DNA hybridisation recently arose during sequence analyses of complete genomes. Genomic comparisons revealed that strains belonging to the same species may contain large amounts (as many as 1.1 Megabasis out of 5) of strain-specific sequences. In the case of Escherichia coli strain O157 analysis surprisingly revealed a large number of prophages (Ohnishi et al. 2001). Such numerous strain-specific sequences could strongly alter the hybridisation rates between 2 strains and consequently lead to misidentification of species.

Our results support the proposal of other investigators that $g y r B$ - based phylogenetic structure comprises an alternative method to DNA-DNA hybridisation for determining the taxonomic relationships of Vibrio splendidus-related strains (Suzuki et al. 1999, Yamamoto et al. 1999). Until the method has been rendered more effective, $g y r B$ sequences could be used to cluster strains, and such clusters could then be validated by DNA-DNA hybridisation using S1-nuclease and $\Delta$ Tm calculation. Other house-keeping genes, e.g. rpoD (Yamamoto \& Harayama 1998) and hsp60 (Kwok et al. 2002), should also be sequenced, incorporating gyrB in a multilocus scheme for the future identification and classification of Vibrio species. Such sequence information would enable the development of molecular diagnostic tools to detect specific species or strains responsible for mortality events.

Acknowledgements. The authors acknowledge Professor J. Swing for providing LMG type strains, Professor B. Austin and Dr. F. Thompson for critically reading the manuscript, and Dr. P. Soletchnik for statistical analyses. This study was carried out with financial assistance from the European Community Reference Laboratory for Bivalve Mollusc Diseases.

\section{LITERATURE CITED}

Baumann P, Schubert RHW (1984) Family II Vibrionaceae Veron 1965, 5245 ${ }^{\text {AL }}$. In: Krieg NR, Holt JG (eds) Bergey's manual systematic of bacteriology. Williams \& Wilkins, Baltimore, p 516-517

Baumann P, Baumann L, Bang SS, Woolkalis MJ (1980) Reevaluation of the taxonomy of Vibrio, Beneckea, and Photobacterium: abolition of the genus Beneckea. Curr Microbiol 4:127-132

Crosa JH, Brenner DJ, Falkow S (1973) Use of a single-strand specific nuclease for analysis of bacterial and plasmid deoxyribonucleic acid homo- and heteroduplexes. J Bacteriol 115:904-911

Farto R, Montes M, Perez MJ, Nieto TP, Larsen JL, Pedersen K (1999) Characterization by numerical taxonomy and ribotyping of Vibrio splendidus biovar I and Vibrio scophthalmi strains associated with turbot cultures. J Appl Microbiol 86:796-804

Fox GE, Wisotzkey JD, Jurtshuk PJ (1992) How close is close: 16S rRNA sequence identity may not be sufficient to guarantee species identity. Int J Syst Bacteriol 42:166-170

Galtier N, Gouy M, Gautier C (1996) SEAVIEW and PHYLO_WIN: 2 graphic tools for sequence alignment and molecular phylogeny. Comput Appl Biosci 12:543-548

Garrity GM, Holt JG (2001) The road map to the manual. In: Boone DR, Castenholtz RW, Garrity GM (eds) Bergey's 
manual of systematic bacteriology, 2nd edn. SpringerVerlag, New York, p 119-166

Gascuel O (1997) BIONJ: an improved version of the NJ algorithm based on a simple model of sequence data. Mol Biol Evol 14:685-695

Gatesoupe FJ, Lambert C, Nicolas JL (1999) Pathogenicity of Vibrio splendidus strains associated with turbot larvae, Scophthalmus maximus. J Appl Microbiol 87:757-763

Grimont PAD (1984) Use of DNA reassociation in bacterial classification. Can J Microbiol 34:541-546

Grimont PAD, Popoff MY, Grimont F, Coynault C, Lemelin M (1980) Reproducibility and correlation study of three deoxyribonucleic acid hybridisation procedure. Curr Microbiol 4:325-330

Gupta RS (1998) Protein phylogenies and signature sequences: a reappraisal of evolutionary relationships among Archaebacteria, Eubacteria, and Eukaryotes. Microbiol Mol Biol Rev 62:1425-1491

Kwok AY, Wilson JT, Coulthart M, Ng LK, Mutharia L, Chow AW (2002) Phylogenetic study and identification of human pathogenic Vibrio species based on partial hsp60 gene sequences. Can J Microbiol 48:903-910

Lacoste A, Jalabert F, Malham S, Cueff A, Gélébart F, Cordevant C, Lange M, Poulet SA (2001) A Vibrio splendidus strain is associated with summer mortality of juvenile oysters Crassostrea gigas in the Bay of Morlaix (North Brittany, France). Dis Aquat Org 46:139-145

Lambert C, Nicolas JL, Cilia V, Corre S (1998) Vibrio pectenicida sp. nov. a pathogen of scallop (Pecten maximus) larvae. Int J Syst Bacteriol 48:481-487

Le Roux F, Gay M, Lambert C, Waechter M, Poubalanne S, Chollet B, Nicolas JL, Berthe F (2002) Comparative analysis of Vibrio splendidus-related strains isolated during Crassostrea gigas mortality events. Aquat Living Resour 15:251-258

Ludwig W, Klenk HP (2001) Overview: a phylogenetic backbone and taxonomic frame work for prokaryotic systematics. In: Boone DR, Castenholtz RW, Garrity GM (eds) Bergey's manual of systematic bacteriology, 2nd edn. Springer-Verlag, New York, p 49-65

Macian MC, Ludwig W, Aznar R, Grimont PA, Schleifer KH, Garay E, Pujalte MJ (2001) Vibrio lentus sp. nov., isolated from Mediterranean oysters. Int J Syst Evol Microbiol 51: $1449-1456$

Nealson KH, Wimpee B, Wimpee C (1993) Identification of Vibrio splendidus as a member of the planktonic luminous bacteria from Persian Gulf and Kuwait region with LuxA probes. Appl Environ Microbiol 59:2684-2689

Nicolas JL, Corre S, Gauthier G, Robert R, Ansquer D (1996) Bacterial problems associated with scallop Pecten maximus larval culture. Dis Aquat Org 27:67-76

Ochman H, Wilson AC (1987) Evolution in bacteria: evidence for a universal substitution rate in cellular genomes. J Mol Evol 26:74-86

Ohnishi M, Kurokawa K, Hayashi T (2001) Diversification of Escherichia coli genomes: are bacteriophages the major contributors? Trends Microbiol 9:481-485

Editorial responsibility: Carey Cunningham, Aberdeen, UK
Sambrook J, Fritsch EF, Maniatis T (1989) Molecular cloning: a laboratory manual, 2nd edn. Cold Spring Harbor, NY

Sneath PHA (1972) Computer taxonomy. Methods Microbiol 7A:29-98

Sneath PHA, Sokal RR (1973) Numerical taxonomy: the principles and practice of numerical classification. WH Freeman, San Francisco, p 188-1308

Stackebrandt E, Goebel BM (1994) Taxonomic note: a place for DNA-DNA reassociation and 16S rRNA sequence analysis in the present species definition in bacteriology. Int J Syst Bacteriol 44:846-849

Stackebrandt E, Frederiksen W, Garrity GM, Grimont PAD and 9 others (2002) Report of the ad hoc committee for the re-evaluation of the species definition in bacteriology. Int J Syst Evol Microbiol 52:1043-1047

Sugumar G, Nakai T, Hirata Y, Matsubara D, Muroga K (1998) Vibrio splendidus biovar II as the causative agent of bacillary necrosis of Japanese oyster Crassostrea gigas larvae. Dis Aquat Org 33:111-118

Suzuki M, Nakagawa Y, Harayama S, Yamamoto S (1999) Phylogenetic analysis of genus Marinilabilia and related bacteria based on the amino acid sequences of $g y r B$ and amended description of Marinilabilia salmonicolor with Marinilabilia agarovorans as its subjective synonym. Int J Syst Bacteriol 49:1551-1557

Thompson FL, Hoste B, Vandemeulebroecke K, Swings J (2001) Genomic diversity amongst Vibrio isolates from different sources determined by fluorescent amplified fragment length polymorphism. Syst Appl Microbiol 24: 520-38

Thompson FL, Thompson CC, Li Y, Gomez-Gil B, Vandenberghe J, Hoste B, Swings J (2003a) Vibrio kanaloae sp. nov., Vibrio pomeroyi sp. nov. and Vibrio chagasii sp. nov., from sea water and marine animals. Int J Syst Evol Microbiol 53:753-759

Thompson FL, Thompson CC, Swings J (2003b) Vibrio tasmaniensis sp. nov., isolated from Atlantic salmon (Salmo salar L.). Syst Appl Microbiol 26:65-69

Waechter M, Le Roux F, Nicolas JL, Marissal E, Berthe F (2002) Characterisation of Crassostrea gigas spat pathogenic bacteria. C R Acad Sci 325:231-238

Watanabe K, Nelson J, Harayama S, Kasai H (2001) ICB database: the $g y r B$ database for identification and classification of bacteria. Nucleic Acids Res 29:344-145

Yamamoto S, Harayama S (1995) PCR amplification and direct sequencing of gyrB genes with universal primers and their application to the detection and taxonomic analysis of Pseudomonas putida strains. Appl Environ Microbiol 61:1104-1109

Yamamoto S, Harayama S (1998) Phylogenetic relationships of Pseudomonas putida strains deduced from the nucleotide sequences of gyrB, rpoD and 16SrRNA genes. Int J Syst Bacteriol 48:813-819

Yamamoto S, Bouvet PJ, Harayama S (1999) Phylogenetic structures of the genus Acinetobacter based on $g y r B$ sequences: comparison with the grouping by DNAhybridisation. Int J Syst Bacteriol 49:87-95

Submitted: July 28, 2003; Accepted: October 21, 2003

Proofs received from author(s): February 23, 2004 